\title{
Applicability and significance of salicylate screening in sera of voluntary blood donors: evaluation of two analytical methods
}

\author{
R SHARON, I FRUTKOFF, G KIDRONI, J MENCZEL \\ From the Hadassah University Hospital, Mt Scopus, Jerusalem, Israel
}

SUMMARY Salicylate concentrations in 3819 sera of apparently healthy voluntary blood donors were determined in view of the significance of this drug in the induction of allergic reactions and its possible interference in platelet function. Two hundred and ninety-five sera were found by a modified colorimetric determination to contain salicylates. The colorimetric determination was compared with a high performance liquid chromatography (HPLC) analysis of salicylate-containing sera. Drug concentrations detected were mostly in the range of $20-100 \mathrm{mg} / \mathrm{l}$. Such concentrations have been reported to evoke allergic reactions and to affect the haemostatic action of platelets.

The blood bank of almost any large hospital is often faced with the problem of a transfusion reaction in a patient receiving a unit of blood or one of its components - for example, packed cells, fresh frozen plasma, cryoprecipitate or platelets. Mild transfusion reactions are characterised by weals, itching, splotchy erythema, tachycardia and, very rarely, fever. ${ }^{1}$ More severe transfusion reactions-though not common, yet unpleasant for both patient and treating physician-are shock-like reactions: hypertension, flushing, wheezing, dyspnoea, abdominal and back pains, frequently chest pains, cyanosis and nausea. These reactions occur within minutes of the commencement of the transfusion. ${ }^{2} 3$

The unit of blood or its component which apparently caused the reaction is returned to the blood bank, together with a fresh sample of the patient's blood, drawn after the onset of the transfusion reaction. ${ }^{4}$ The first step undertaken in the blood bank on such occasions is the performance of a direct antiglobulin test, aimed at detecting red cells coated with antibody, which would be present in cases in which mismatched blood has been transfused.

The next step would be a repeat screening of the patient's serum for antibodies which might have been missed by the first screening, together with a repeated cross match of the patient's serum with the donor's red cells. Commonly, all these tests prove to be negative. ${ }^{5}$

Another possible reason for transfusion reactions of the anaphylactoid type is the transfusion of blood

Accepted for publication 20 May 1981 or plasma containing IgA to a patient who lacks this immunoglobulin. ${ }^{6}$

Transfusion reactions may also be caused by antibodies directed against antigens present on human leucocytes and platelets. These reactions of the anti-HLA (human leucocytic antigens) antibodies are common in patients with chronic diseases who receive transfusions regularly. The commonest procedures to prevent such reactions are the removal of the buffy coat from the blood unit, or the use of frozen blood which was washed after thawing. HLA matching of donor's and recipients' blood is not a routine procedure in hospital blood banks. ${ }^{7}$

If all the above causes for a transfusion reaction have been ruled out, then an allergic reaction towards a drug carried by the transfused blood or blood component must be considered. The policy of every blood bank is to question each and every blood donor about his use of drugs, in accordance with the Criteria for the Selection of Blood Donors of the International Society of Blood Transfusion (Paris, 1976). Blood donors are generally unaware of the danger of transfusing drug-containing blood, and thus some donors may still fail to give all relevant details, despite direct questioning.

For the past four years, the Blood Bank of Hadassah University Hospital, Mt Scopus, in collaboration with the Department of Microbiology and the Research Laboratory of the Department of Internal Medicine, has been involved in the investigation of drug-related transfusion reactions (such as penicillins, sulfomamides) and their aetiology. ${ }^{8}$ The well-documented role of salicylates in the induction 
of allergic reactions ${ }^{9}$ and damage to the haemostatic effects of platelets ${ }^{1011}$ led us to include this drug in the screening of blood donors' sera; further motivation to do so lies in the widespread use among the general public of aspirin, a drug obtainable without a doctor's prescription. The objectives of the investigation presented below were to determine the frequency of salicylate detection in a large sample of sera obtained from healthy blood donors, and to establish a fast, simple, yet dependable salicylatescreening procedure which would be an easilyapplicable routine in a hospital blood bank.

\section{Material and methods}

Blood plasma samples were screened for salicylates by the rapid colorimetric method of Trinder, ${ }^{12}$ as adapted by Hanok. ${ }^{13}$ The preparation of the colour reagent was modified; instead of first dissolving mercuric chloride in hot water, which could lead to the hazardous sublimation of mercuric chloride, advantage was taken of its increased solubility in acidic solution. Hydrochloric acid $(120 \mathrm{ml} 1 \mathrm{~N})$ was added to $850 \mathrm{ml}$ of deionised water; $40 \mathrm{~g}$ of mercuric chloride were added with vigorous stirring for $30 \mathrm{~min}$ at room temperature, followed by $40 \mathrm{~g}$ of ferric nitrate $\left(9 \cdot \mathrm{H}_{2} \mathrm{O}\right)$. The volume was then adjusted to one litre with deionised water. All reagents were of analytical grade.

The Hanok method ${ }^{13}$ used $\mathbf{0} \cdot 1 \mathrm{ml}$ serum or plasma and $4.0 \mathrm{ml}$ of colour reagent. The purple colour which developed in the presence of salicylates was read with special long light path cuvettes. This method was further modified by us so that use could be made of regular $1.0 \mathrm{~cm}$ light path cuvettes. This was achieved by the addition of $4.0 \mathrm{ml}$ of the above colour reagent to $0.4 \mathrm{ml}$ plasma samples. The colour which was generated was linear in the range of $50-300 \mathrm{mg} / \mathrm{l}$ salicylic acid and stable for at least $75 \mathrm{~min}$ at room temperature. Even concentrations of $20 \mathrm{mg} / \mathrm{l}$ could be detected.

Colorimetric results were verified by high performance liquid chromotography (HPLC). Plasma samples $(200 \mu \mathrm{l})$ were extracted by the method of Lo and Bye. ${ }^{14}$ Extracts were taken to dryness under nitrogen on ice and the residue was taken up in $50 \mu \mathrm{l}$ of mobile phase. Aliquots $(10 \mu \mathrm{l})$ were analysed by HPLC. Samples were run in a mobile phase of $0.02 M$ sodium acetate-methanol $(9: 1$ by volume), pH 6.8-7.0 (adjusted with $4 \mathrm{~N}$ acetic acid), on a $0.46 \times 25 \mathrm{~cm}$ column of Merck LiChrosorb RP-8 at $1.6 \mathrm{ml} / \mathrm{min}(80 \mathrm{~atm})$. Retention times under these conditions were: aspirin $4.9 \mathrm{~min}$, salicylic acid 7.4 min and 8-chlorotheophilline (internal standard) $9.7 \mathrm{~min}$. Detection was by ultraviolet absorbance at $254 \mathrm{~nm}$ with a sensitivity of 0.01 AUFS (absorbance units full scale). Quantification was by peak height measurement. A $10 \mathrm{mg} / \mathrm{l}$ standard gave a peak height of $1.3 \mathrm{~cm}$, and limit of detection $(5 \times$ noise level) was about $1.5 \mathrm{mg} / \mathrm{l}$. The average recovery of salicylic $\overline{0}$ acid was $85 \%$.

\section{Results}

Our modified version of the Hanok colorimetric $\operatorname{method}^{13}$ was used to detect salicylate in a total of 3819 plasma serum samples obtained from voluntary blood donors collected between January 1979 and May 1980. All these donors had signed statements indicating no use of any drug in the two weeks before donation.

As aspirin is rapidly converted into salicylic acid in an aqueous environment (including blood plasma), determination of salicylate by the colorimetric method probably accounted for all the aspirin ingested by the donors. Salicylic acid was detected in $7.7 \%$ of the sera screened ( 295 out of 3189 serasee Table). About $30 \%$ of the sera contained minute

Salicyclic acid concentrations as determined by the colorimetric method. Of 3819 sera analysed, $295(7.7 \%)$ were salicylate-positive

\begin{tabular}{lcc}
\hline $\begin{array}{l}\text { Salicylate } \\
\text { concentration }(\mathrm{mg} / \mathrm{l})\end{array}$ & No of samples & $\begin{array}{l}\text { Percentage of } \\
\text { total }(\%)\end{array}$ \\
\hline$\leqslant 20.0$ & 90 & 30.5 \\
$\leqslant 50.0$ & 180 & 61.0 \\
$\leqslant 100.0$ & 25 & 8.5 \\
Total & 295 & 100.0 \\
\hline
\end{tabular}

amounts of salicylate-up to a concentration of $20 \mathrm{mg} / \mathrm{l}$ - while the majority $(61 \%)$ were in the $50 \mathrm{mg} / \mathrm{l}$ concentration range. Concentrations from $50 \mathrm{mg} / \mathrm{l}$ to $100 \mathrm{mg} / \mathrm{l}$ were detected in only $8.5 \%$ of the salicylate positive sera (Table). Random samples of sera were subjected to HPLC verification of the colorimetric measurements. The methodology chosen for HPLC analysis ${ }^{14}$ allowed the recovery and quantification of both aspirin and salicylic acid in the same sample, while the colorimetry preferentially detected salicylic acid only. About 30 sera which were devoid of salicylate according to the colorimetry were verified by HPLC to be free of either aspirin or salicylic acid. HPLC determinations on colorimetrically positive sera verified the presence of salicylic acid in every sample tested. The Figure shows, however, that there was not a complete quantitative agreement between both analytical methods. Although all samples were positive by both methods, in most instances the colorimetry gave an overestimate of salicylic acid concentration. 


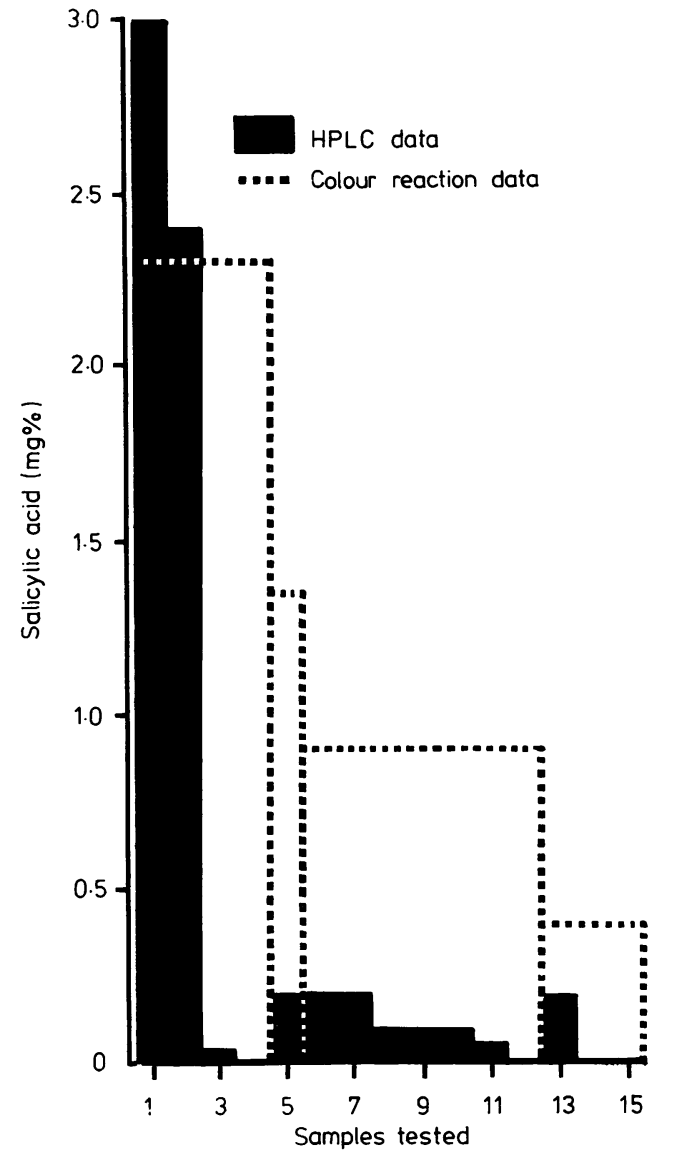

Comparison of HPLC and colorimetric determinations of salicylic acid concentrations in a group of salicylatepositive plasma samples. In samples 4, 12, 14 and 15 only trace amounts of salicylate were detected by HPLC quantification.

\section{Discussion}

The relatively high incidence $(7 \cdot 7 \%)$ of salicylate in the sera of 3819 healthy blood donors tested (Table) is indicative of the ubiquitous utilisation of aspirin among the general population and also emphasises the importance of monitoring blood units for popular drugs with potential adverse side effects, ${ }^{15}$ which may be hazardous to recipients of blood or blood components-for example, penicillin, sulfonamides, barbiturates, meprobamate. Transfusion reactions caused by a blood unit containing penicillin have been described, 8 although the incidence of penicillin or its derivatives among healthy blood donors was found to be more than twentyfold lower $^{16}$ than the frequency of salicylate detection described above. The majority of the serum samples which contained salicylate had concentrations of $50 \mathrm{mg} / \mathrm{l}$ or less $(91.5 \%$ of the cases, Table). These findings suggest that allergic reactions might be the main adverse effect of salicylate-containing transfusions of blood or blood components. Allergic reactions to salicylate are caused in $1-4 \%$ of the general population ${ }^{17}$ and in $8-25 \%$ of asthma patients. ${ }^{18}$

In a recent case in our hospital, a 25-year-old woman suffering from postpartum haemorrhage developed urticaria and pruritus during the transfusion of a single unit of blood. This adverse effect could not be attributed to mismatching of blood types or to the presence of antibiotics. However, the blood unit was found to contain about $20 \mathrm{mg} / \mathrm{l}$ aspirin. The patient was unaware of any aspirin intolerance, but a mast cell degranulation test ${ }^{19}$ proved her to be allergic to this drug.

A variety of salicylate concentrations have also been implicated in disturbances of the haemostatic effect of platelets. ${ }^{2021}$ This fact is important, since one of the main objectives of a hospital blood bank is aiding the physician in the prevention or elimination of problems of blood clotting, either before or during an operation. The blood components most commonly used for that purpose are platelets which were separated from a blood unit within four hours of donation. While an adult thrombopaenic patient usually receives a pool of six units of platelet concentrates which, due to the dilution, may reduce the effect of salicylate on platelet function, neonates may receive only a single unit of platelet concentrate (30-50 $\mathrm{ml}$ by volume) and in a case where this happened to contain salicylates, it could be defective. Another high-risk patient population consists of those who are subjected to frequent transfusionsfor example, haemophiliac patients or patients suffering from thalassaemia.

Platelets have to be used within $72 \mathrm{~h}$ of blood donation, while whole blood or packed red blood cells can be administered within 21 days. Cryoprecipitate (antihaemophilic factor) or fresh frozen plasma, on the other hand, may be kept frozen and used after two years if stored at $-20^{\circ} \mathrm{C}$ to $-40^{\circ} \mathrm{C}$ or after an even longer period of time, if stored at $-70^{\circ} \mathrm{C}$. These standard practices of blood banks emphasise the need for a routine salicylate screening of sera in view of the chemical stability of salicylic acid under such storage conditions. As even trace amounts of salicylate may cause allergies, the elimination of salicylic acid-containing blood units is strongly advocated. For that purpose, the establishment of a screening routine for salicylates in blood units is recommended.

The colorimetric method, as performed in this 
study, can easily be used for fast, routine screening of large quantities of blood units employing standard laboratory equipment. The reliability of this method was checked by comparison with the much slower and more tedious, but very accurate and more sensitive quantification by the HPLC. This methodology appears to have adequate sensitivity for the minute quantities of salicylate which are enough to elicit a relatively mild allergic reaction, as in the case described above.

We found the colorimetric reaction to be reliable for the qualitative detection of salicylic acid in sera, with no false-positive results being produced. As far as quantification was concerned, inconsistencies were detected between the two procedures (Figure). This, however, is of academic significance only; for practical purposes the mere detection of salicylate in the blood unit is the most important consideration. The high performance liquid chromatography, though not always routine in blood banks, could, however, be the analytical method chosen whenever interference by salicylate is suspected after the administration of an ineffective thrombocyte transfusion.

On the basis of the above discussion, we conclude that a routine prevention measure to eliminate salicylate transfusion can be carried out by colorimetric screening of donors' sera. In institutions where such a measure is not routine practice, precautions should be taken by performing salicylate analysis of blood units which are prepared for transfusion to asthmatic patients, patients known to suffer from aspirin hypersensitivity, or for platelet concentrates prepared for transfusion to thrombopaenic neonates.

In view of the high incidence of salicylates which we detected among blood donors, the screening of donor sera for other drugs which could be harmful to recipients might be of interest.

\section{References}

${ }^{1}$ Stephen CR, Martin RC, Bourgeois-Gavardin M. Antihistaminic drugs in treatment of nonhemolytic transfusion reactions. $J A M A$ 1955; $158: 525$.

2 Fudenberg HH. In: Merler E, ed. Immunoglobulins. Washington DC: National Academy of Science Publication, 1970.

${ }^{3}$ Vos GH, Downing HJ, Vos D. The incidence of antibodies to leukocytes and gammaglobulin IgG and IgA in a $\stackrel{\stackrel{0}{5}}{0}$ population of multitransfused Southern African Negroes. Transfusion 1973;13:437.

${ }^{4}$ Mollison PL. Blood transfusion in clinical medicine. London: Blackwell, 1972:12.

${ }^{5}$ Sherwood GK. In: Ben Dawson R, ed. New approaches to transfusion reactions. Washington: American Association $\overline{\bar{c}}$ of Blood Banks, 1974:1.

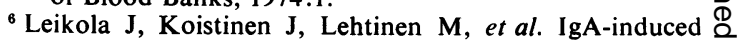
anaphylactic transfusion reactions: a report of four cases. Blood 1973;42:111-9.

${ }^{7}$ Perkins HA, Payne R, Ferguson J, et al. Non-hemolytic $\vec{\circ}$ febrile transfusion reactions, quantitative effects of $\rightarrow$ blood components with emphasis on isoantigenic $\vec{\omega}$ incompatibility of leukocytes. Vox Sang 1966;11:578-600. O

${ }^{8}$ Michel J, Sharon R. Non-haemolytic adverse reaction $\overline{0}$ after transfusion of a blood unit containing penicillin. Br Med J 1980;280:152-3.

${ }^{9}$ Fein BT. Aspirin shock associated with asthma and nasal polyps. Ann Allerg 1971;29:598-601.

${ }^{10}$ Evans G, Packham MA, Nishizawa EE, Mustard JF, Murphy EA. The effect of acetylsalicylic acid on $\frac{\text { O }}{\supset}$ platelet function. J Exp Med 1968;128:877-94.

11 Weltman JK, Szard RP, Settipane GA. An analysis of the $\bar{c}$ role of IgE in intolerance to aspirin and tartrazine. ฏ Allergy 1978:34:273-81.

12 Trinder P. Rapid determination of salicylates in biological fluids. Biochem $J$ 1954;57:301-3.

${ }^{13}$ Hanok A. The ultramicro determination of salicylates in biological fluids. Clin Chem 1962;18:400-4.

${ }^{14}$ Lo LY, Bye A. Specific and sensitive method for the determination of aspirin and salicylic acid in plasma using reverse-phase high performance liquid chromatography. J Chromatogr 1980;181:473-7.

${ }^{15}$ Martin EW. Hazards of medication. Philadelphia: Lippincott, 1971:321-77.

${ }^{16} \mathrm{Michel} \mathrm{J}$, Sharon R. Detection of penicillin in the blood of $\Omega$ "healthy" blood donors. Vox Sang 1980;38:19-21.

17 Porter J, Jick H. Drug-induced anaphylaxis, convulsions, deafness and extrapyramidal symptoms. Lancet 1977 ;i: 587-8.

18 Patterson R. Allergic diseases, diagnosis and management. Philadelphia: Lippincott, 1972:473.

19 Perelmutter L, Khera K. A study on the detection of $\frac{?}{0}$ human reagins with rat peritoneal mast cells. Inı Arch Allergy Appl Immunol 1970;39:27-44.

${ }_{20}$ Moore BPL, Freiesleben E, Hogman CF. Criteria for the selection of blood donors. Washington: International $\mathrm{O}$ Society for Blood Transfusion, 1976.

21 Paccioretti MJ, Black LH. Effects of aspirin on platelet $O$ aggregation as a function of dosage and time. Clin Pharmacol Ther 1980;27:803-9.

Requests for reprints to: $\operatorname{Dr} \mathbf{R}$ Sharon, Hadassah $N$ University Hospital, Mt Scopus, Jerusalem, Israel. 